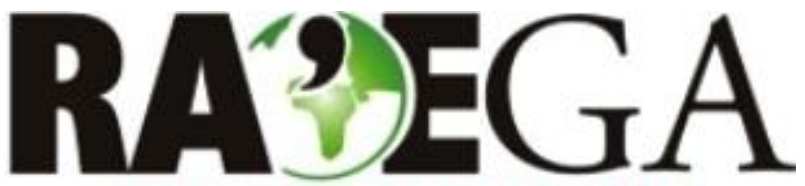

O ESPACO GEOGRÁFICO EM ANÁLISE

\author{
O MAPA COMO RELATO
}

\title{
THE MAP AS ACCOUNT
}

Renata Moreira Marquez

Departamento de Análise Crítica e Histórica

Escola de Arquitetura e Design

Universidade Federal de Minas Gerais Belo Horizonte, MG,

e-mail: renamarquez@gmail.com / www.geografiaportatil.org

Recebido em: 01.09 .2013

Aceito em: 05.02.2014

\section{Resumo}

Este ensaio propõe uma reflexão crítica sobre o mapa como modelo privilegiado de representação do espaço. Partindo da iconografia historicamente verificada com a disseminação do imaginário do globo terrestre e buscando os possíveis estratos heterotópicos ou margens de desobediência cartográfica atuantes nos mapas existentes bem como na emergência de novos mapas, aborda algumas das suas transformações históricas na tensão constantemente experimentada entre inventário e invenção, através de um conjunto selecionado de reflexões e proposições de autores vindos não da geografia mas das artes visuais e da literatura tais como Joaquín Torres-García, Georges Perec, Joan Brossa, Julio Cortázar e outros. Frente à análise da aplicabilidade do mapa como relato subjetivo e da sua aproximação com uma experiência cartográfica múltipla e diversa capaz de inventariar, nos lugares estudados, a qualidade poética da vida, o mapa ressurge, assim, como ciência das qualidades em detrimento de campo das quantidades. Propõe-se, conclusivamente, repensar a cartografia como uma plataforma científica que, mesmo nas suas origens, já guardava uma potência mítica para relatos abertos e transversais à ciência e que, no contexto atual, pode tornar-se uma plataforma de ação criativa em prol de novas sensibilidades perceptivas, novos mundos estéticos e novos movimentos prospectivos de transformação imaginativa do espaço, ampliando e complexificando o esforço de conhecer as nossas relações geográficas.

Palavras-chave: cartografia como ciência das qualidades; arte e ciência; heterotopia. 


\begin{abstract}
This essay proposes a critical reflection on the map as a privileged model of spatial representation. Departing from the iconography historically verified with the spread of the imaginary of the globe and seeking possible heterotopic strata or margins of active disobedience on existing cartographic maps as well as in the emergence of new maps, this article addresses some of the historical transformations constantly experienced in the tension between inventory and invention through a selected set of reflections and propositions of authors not from geography but from the fields of visual arts and literature such as Joaquín Torres-García, Georges Perec, Joan Brossa, Julio Cortázar and others. Through the analysis of the applicability of the map as subjective report and its approach to a multiple and diverse cartographical experience capable of inventorying, at studied locations, the poetic quality of life, the map reappears as a science of qualities at the expense of a field of quantities. We propose conclusively to rethink cartography as a scientific platform that, even in its origins, has kept a mythical power to open and transverse science reports and that in the current context can become a platform for creative action in favor of new perceptual sensitivities, new aesthetic worlds and new prospective movements of imaginative transformation of space, expanding and complexifying the effort to understand our geographical relationships.
\end{abstract}

Key words: cartography as science of qualities; art and science; heterotopia.

\title{
INTRODUÇÃO
}

A cartografia pode ser repensada como uma plataforma científica que, mesmo nas suas origens, já guardava uma potência mítica para relatos abertos e transversais à ciência? Pode-se compreender que, no contexto atual, ela possa tornar-se uma plataforma de ação criativa em prol de novas sensibilidades perceptivas, novos mundos estéticos e novos movimentos prospectivos de transformação imaginativa do espaço, ampliando e complexificando o esforço de conceber as nossas relações geográficas?

O olhar vertical, astúcia do observador que idealmente habita o exterior do mundo numa posição panóptica, é a contradição constituinte de todo mapa. Concebido a partir de dentro, o mapa ecoa o fora do mundo, a sua feição onírica que só se tornou imagem observada com a real experiência da vista da Terra no ano de 1969. Antes disso, o imaginário do olhar vertical ou a iconografia do globo - através da divina distância dos olhos de Apolo, como escreveu Denis Cosgrove - ajudava a dar forma e sentido ao espaço vivido. 
O globo é uma figura de enorme poder imaginativo; até 1968 ver a esfera da Terra significava imaginá-la ou representá-la, uma atividade frequentemente inseparável da experiência visionária. Alcançar a visão global é perder as conexões com a Terra, escapar do entrave do tempo e dissolver as contingências da vida cotidiana em favor de um momento universal de devaneio e harmonia. (COSGROVE, 2001, p.3)

Simultaneamente instrumento de leitura e escritura da Terra, pode-se perceber no mapa a tensão entre espaço inventário e espaço inventado, tal como enunciou Georges Perec: por um lado, a operação cartográfica coleta, acumula e classifica cada lugar e cada forma existente num panorama desabitado; por outro, técnicas e poéticas de representação se ocupam em criar mundos. "Espaço inventário, espaço inventado: o espaço começa com esse mapa modelo que, nas antigas edições do Petit Larousse, representava em $60 \mathrm{~cm}^{2}$ cerca de 65 termos geográficos milagrosamente juntos, deliberadamente abstratos" (PEREC, 2007, p.34).

John Brian Harley, consciente da importância do mapa como um sistema cultural e, por outro lado, crítico quanto à sua aderência às mudanças tecnológicas e ao fortalecimento dos seus pressupostos positivistas, escreveu que "As palavras ortodoxas no seu vocabulário são 'imparcial', 'objetiva', 'científica' e 'verdadeira', mas raramente se capturam as ressonâncias de classe, gênero, raça, ideologia, poder e conhecimento, ou mito e ritual" (HARLEY, 1992, p.231-232).

Doreen Massey aponta a insuficiência de pensar o espaço como representação de uma multiplicidade discreta (divisível, segmentada, metrificada), sem vida, formada a partir da herança cultural de Henri Bergson que contrapôs o espaço ao tempo. Para Bergson, o tempo seria o domínio do encontro, dos processos, do contínuo em vez do discreto; o espaço seria caracterizado como multiplicidade discreta, sem duração, instantânea, estática. Massey provoca o desejo de pensar sobre o espaço de um outro modo, de expandir a definição tradicional de espaço proveniente das ciências naturais em direção à dimensão de uma multiplicidade de durações: "O problema é que a caracterização conotacional do espaço através da representação, não apenas discreta, mas também sem vida, provou ser forte" (MASSEY, 2008, p.48). Assim, a autora questiona a equivalência entre espaço e representação, uma vez que esta última, para ela, está 
frequentemente conectada a um fechamento ideológico, a uma hegemonização. Ela pergunta: "Seriam os mapas um arquétipo de representação?" (MASSEY, 2008, p.159).

Mas de que mapas se fala? A limitação de equivalência estaria realmente no mapa como arquétipo em si? Ora, sabe-se que os mapas, por ocasião da difusão e popularização das cartas utilitárias, cartas de localização baseadas no acúmulo de dados e operações métricas, tiveram estorvada a sua tradição de serem veículos de terras desconhecidas. A antiga história da cartografia registrava sempre e também a porção de terra do domínio dos dragões - hic sunt dracones - e ela pode ser retomada, atualizada e posta a operar de novo a qualquer momento.

Localizar-se é um esforço complexo o suficiente para gerar inúmeras formas de linguagem e de representação. Esse esforço amplia-se para fora do campo disciplinar da geografia expandindo-o em contato com outros campos. A representação, no campo das artes, não é sinônimo de fechamento ideológico e hegemonização mas exatamente o seu contrário. Como campo experimental de liberdade crítica, a arte compartilha o interesse ainda atual pelo espectro do desconhecido inerente ao espaço. Ainda, e sobretudo hoje, é importante se perguntar: os seres humanos seriam capazes de reconhecer abismos, guerrear contra dragões contemporâneos e delimitar novos territórios desejados? O que se perde no caminho traçado pela ciência? O problema da equivalência entre espaço e representação não está na aplicação do mapa em si mas na negação da sua amplitude de mapa-como-relato ou na sua convenção hegemônica de mapa-de-umrelato-só.

O mapa de Beato (figura 1), desenhado originalmente na Alta Idade Média pelo monge espanhol Beato de Liébana, é um exemplo de mapa T-O ou orbis terrae. De matriz circular, a imagem do mapa T-O traz uma projeção da massa sólida da terra habitada. Os continentes - Ásia, Europa e África - aparecem como domínios dos filhos de Noé (Sem, Jafé e Cam); o T são os mares que dividem os continentes - Mediterrâneo, Vermelho e Negro - e o O é o oceano, moldura do mundo e interface incerta entre as temperaturas propícias da parte do globo onde estão os três continentes e a sua antípoda considerada inóspita. Nos mapas medievais, Jerusalém era representada no centro do mapa e o Jardim do Éden era situado no 
extremo leste da Ásia, parte superior do mapa. O mapa medieval era um modo visual de escrever a história do mundo, ao contrário de ser um mapa métrico tal com o qual o leitor está familiarizado: mapas sob o propósito da localização geométrica e da navegação, para o movimento seguro de um ponto a outro.

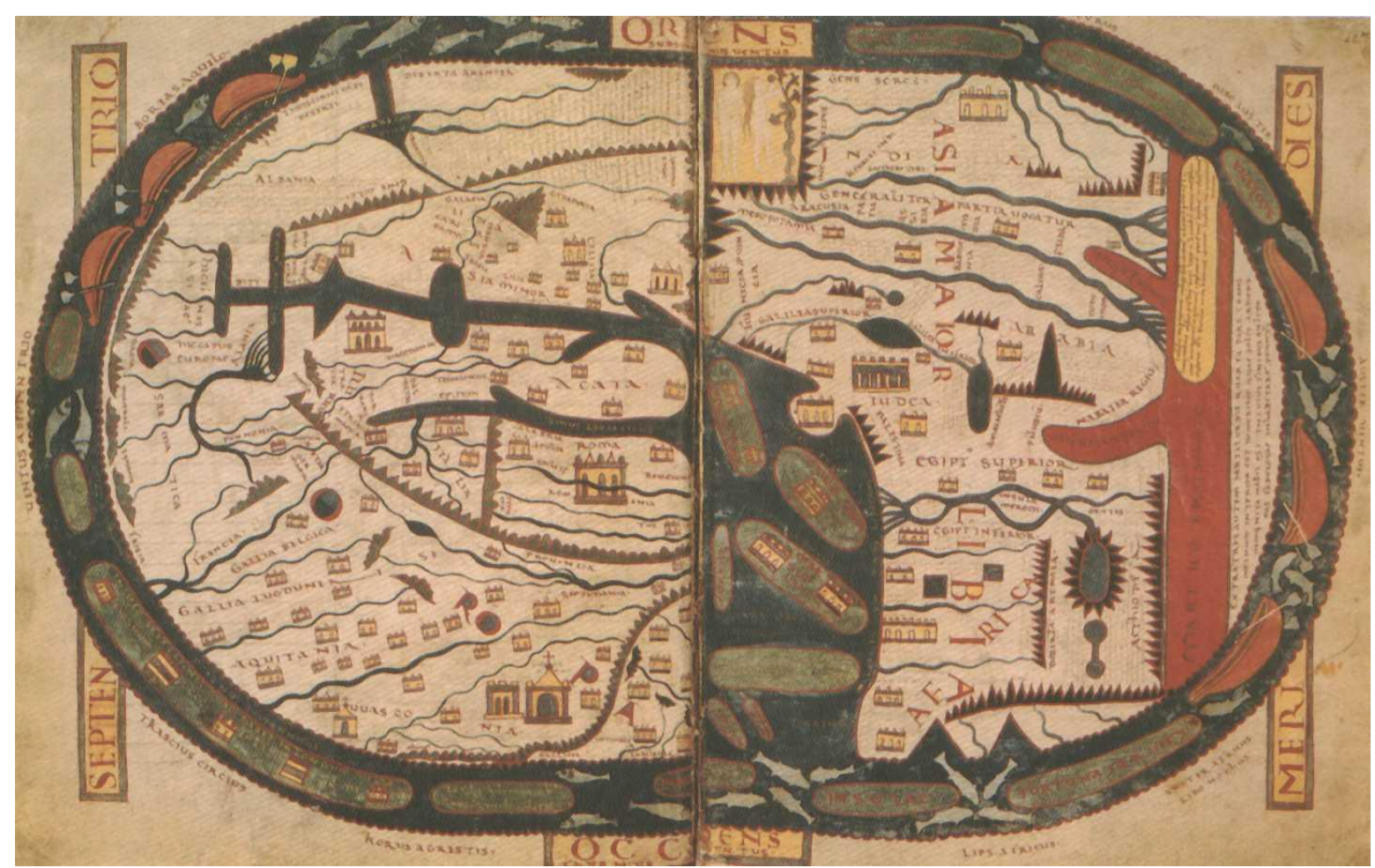

Figura 1 - Mapa de Beato (data do original desconhecida) ${ }^{1}$

Os portulanos, cartas náuticas que apareceram já no final da Idade Média, tinham essa função de navegação e foram usadas originalmente na Itália, Portugal e Espanha, países protagonistas das grandes navegações rumo às Américas (figura 2). Com o acesso, no século XV, ao trabalho de Ptolomeu, desenvolvido na Grécia Antiga, e com a possibilidade de difusão da imprensa, os mapas se popularizaram como guias de navegação e como instrumentos de bordo. Com as navegações, o território conhecido pela Europa se relativiza e se expande e os mapas começam a incorporar novos espaços físicos bem como novos espaços matemáticos de representação. O mapa de então é um desenho aberto que é, lentamente, completado - no desejo do relato de totalidade e globalização - na medida em que as expedições são concretizadas. Mercator apresenta a projeção cilíndrica em 1569,

\footnotetext{
${ }^{1}$ http://upload.wikimedia.org/wikipedia/commons/9/92/ApocalypseStSeverFolios45v46rWorldMap.jpg
} 
ampliando o estudo das latitudes e das longitudes de Ptolomeu, mas apenas no século XVIII, com a invenção de instrumentos de medição e o conhecimento da declinação magnética, ela é largamente adotada na navegação.

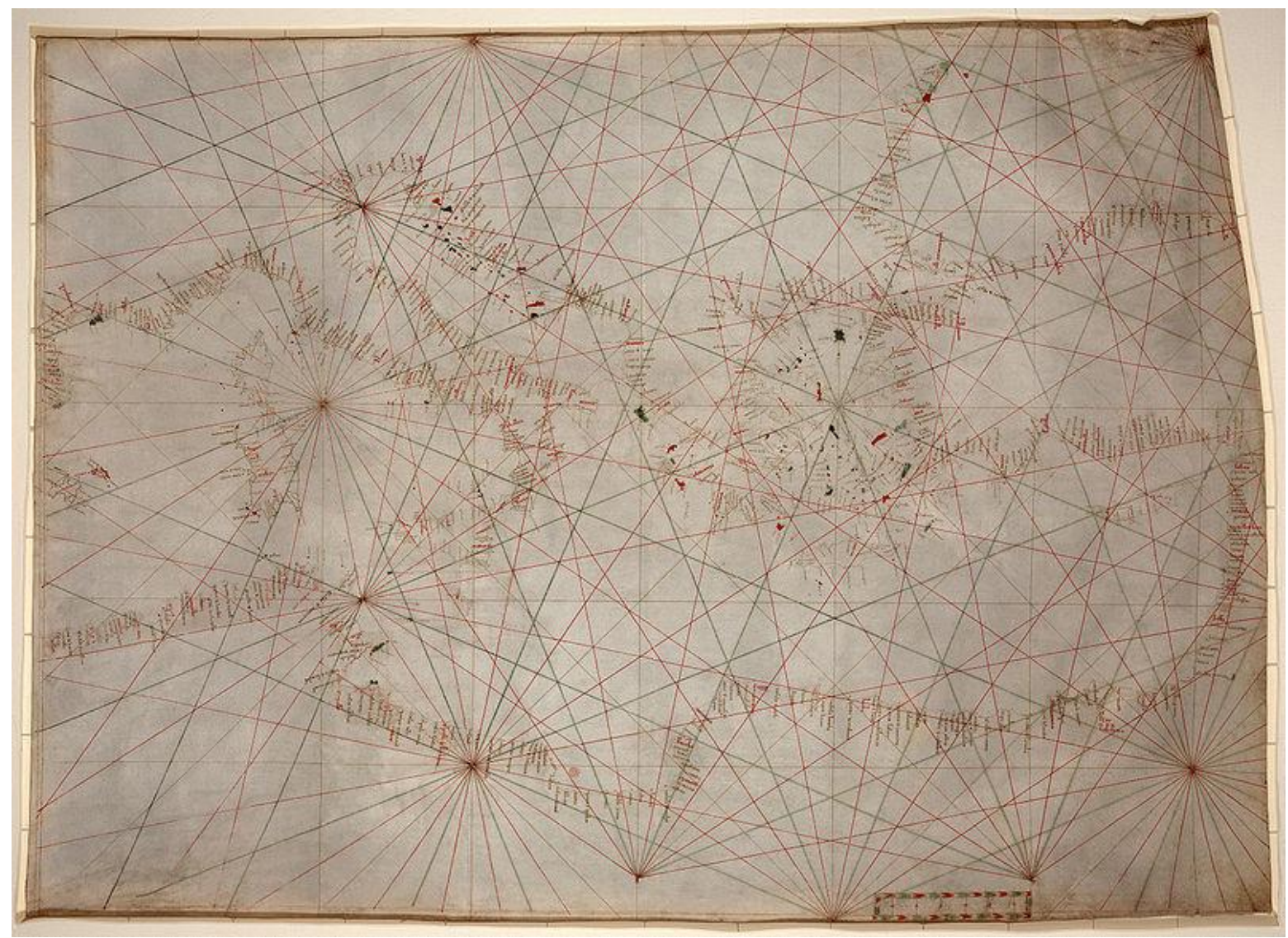

Figura 2 - Portulano do Mediterrânea (século XIV)²

Os mapas modernos de Mercator (figura 3) vão gerar a insaciável coleção de mapas dos quais hoje os leitores se sentem, frequentemente, emersos. O mapa, esse lugar abstrato e onde não figuram pessoas e objetos reconhecíveis pela escala do cotidiano, muitas vezes encarna a coincidência: mapear é colonizar, mapear é dominar. O mapa, como testemunha a sua história ilustrada, foi concebido sempre como uma forma de relato, seja ele uma cartografia mítica ou colonizadora.

\footnotetext{
${ }^{2}$ http://en.wikipedia.org/wiki/File:Mediterranean_chart_fourteenth_century2.jpg
} 


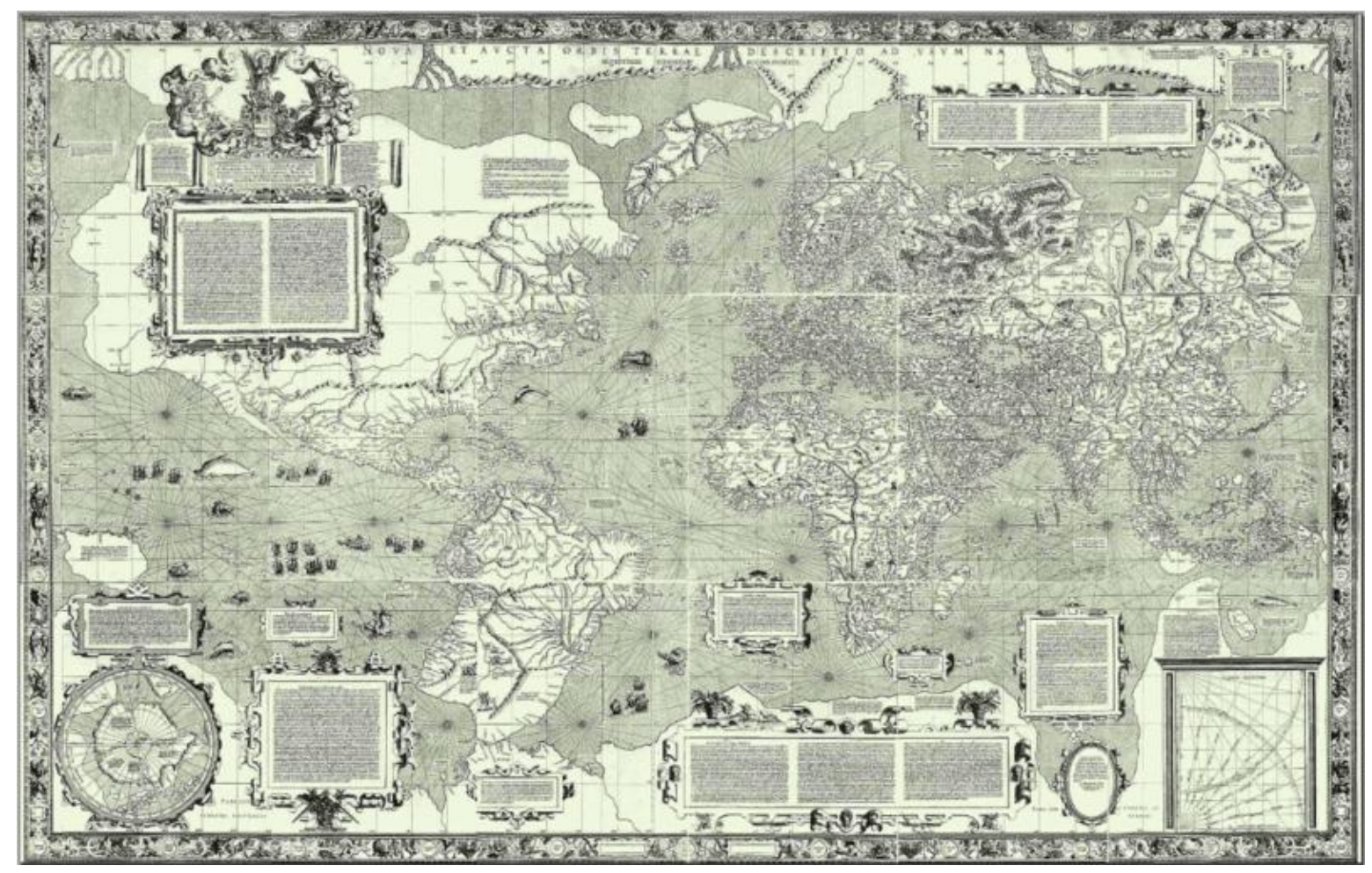

Figura 03 -.Mapa-múndi de Mercator (1569) ${ }^{3}$

\section{DESENVOLVIMENTO: MAPAS HETEROTÓPICOS}

Mas se mapear é instrumentalizar o mundo, os caminhos traçados nessa ação são frequentemente desobedecidos. A margem da desobediência cartográfica é o estrato heterotópico que ainda constitui um desafio à representação de todo mapa. As heterotopias angustiam o exercício cartográfico e minam a estabilidade esquemática do mapa inventário. Os estratos heterotópicos do mapa combatem a ausência do cartógrafo - os olhos de Apolo - com o seu oposto: concebem tentativas de povoar o mapa e criar linhas de força que guiam a percepção do mapa para sobreleituras, sobrerrotas e sobrepovoamentos num exercício de representação de uma multiplicidade de durações.

Extravios cartográficos são propostos por cartógrafos conscientes do poder de discurso e críticos quanto à autoridade nada inocente da formação de um pensamento de mundo inerente ao mapa. Todo mapa reflete o seu ponto de vista cultural, traça o mundo a partir das relações do lugar de onde é visto. Desde o início do século $\mathrm{XX}$, no contexto das Vanguardas Históricas, passando pelos mapas

\footnotetext{
${ }^{3}$ http://en.wikipedia.org/wiki/File:Mercator_1569.png
} 
situacionistas da metade do século XX, aparecem imagens de mapas de extravio, mapas do desejo, mapas heterotópicos. Denis Cosgrove e Luciana Martins chamaram essa categoria de mapeamento de mapas performativos, introduzindo o pensamento relacional e local no lugar do pensamento fixo ou universalista.

Com este termo, nos referimos aos meios nos quais o genius loci, a capacidade que possuem lugares particulares de comunicar um significado intenso e único através do espaço e do tempo, é ativamente feito e refeito. [...] O mapeamento performativo implica a convergência contemporânea entre a atividade artística e a atividade acadêmica geográfica, simultaneamente entendendo e ativando espacialidades [...] (COSGROVE; MARTINS, 2001, p.170).

Num mapa de 1929 feito pelo grupo surrealista de Bruxelas, O mapa do mundo na época dos Surrealistas, notam-se alguns (des)ajustes (figura 4). Os Estados Unidos praticamente desaparecem, invadidos pelo México; vários dos conhecidos países têm o seu tamanho alterado; a Europa é reduzida a poucos Estados e a linha do Equador titubeia, elástica, como se não aceitasse a sua posição fixa média, norma adotada para que se fugisse da dificuldade de representar uma linha imaginária que é inconstante devido à oscilação do eixo de rotação da Terra. Como linha imaginária e também inconstante, o Equador surrealista apenas aplica as suas qualidades geodésicas mais quantitativas.

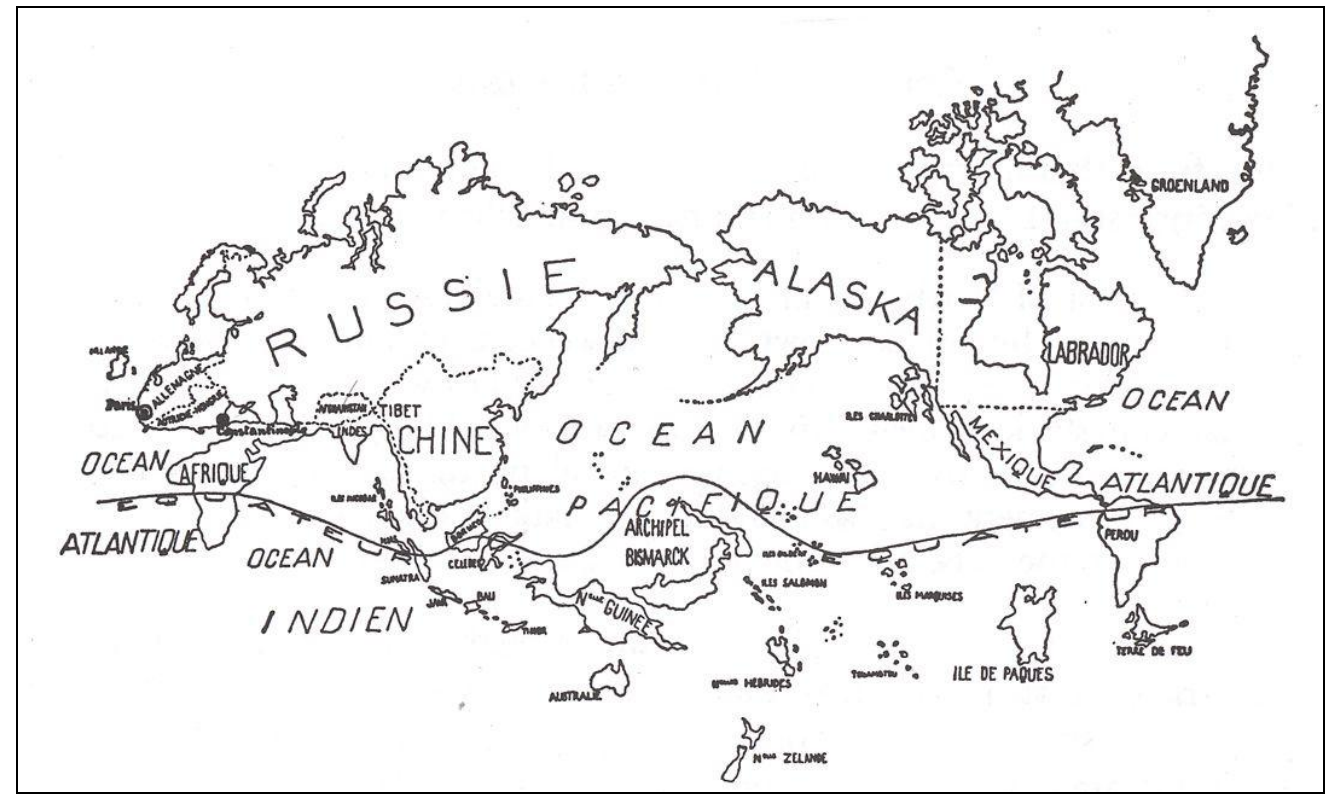

Figura 4 - Mapa surrealista do mundo $(1929)^{4}$

\footnotetext{
${ }^{4}$ http://strangemaps.files.wordpress.com/2008/03/woodpowermaps199313.jpg
} 
Outra constatação no mapa dos surrealistas belgas é que o ponto de vista central escolhido para representar o mapa do mundo coincide com aquele ponto menos importante no qual, para a construção do mapa-múndi ocidental, o globo é abstratamente rasgado e aberto para que assim se comporte como um plano: justamente aí, entre o Alasca e a Rússia, encontra-se o novo centro do mapa-múndi surrealista. Onde o mundo é separado, os surrealistas o reconectam: ainda se trata do plano da abstração.

O grupo, encabeçado por Nougé - bioquímico de profissão - recusa o automatismo psíquico e substitui a arbitrariedade e o acaso pela análise. O objet trouvé dos franceses, o "objeto tropeçado" mais que "encontrado", acaba sendo para os belgas um objet bouleversant, algo que tem que ser construído, que tem que ser inventado. (DIEGO, 2008, p. 11).

Em clara contraposição à doutrina surrealista de André Breton, ecoada de Paris, os surrealistas belgas optam pela análise das formas do mundo e a complexidade do ato de observar e de fazer ver. A deformação do relato que propõe o grupo de Paul Nougé subverte o mapa-mundi convencional evidenciando a sua operação estratégica e traça o mundo a partir do que considera como o seu centro, conformando-se através de novas linhas de poder e práticas culturais contrahegemônicas e anticolonialistas.

Joaquín Torres García traça em 1943 o mapa da América Invertida, desde a perspectiva de sua cidade, Montevidéu (figura 5). No mapa de Torres García há ícones, coordenadas e a linha imaginária que divide a Terra nos hemisférios setentrional e meridional. Mas o seu potencial de linha imaginária é mais uma vez posto para funcionar, concebendo outras ordenações para o mundo. A linha se fixa mas agora é o território que se inverte tendo-a como eixo de rotação.

Como escreve em 1935 em La Escuela del Sur, localizar-se é entender as relações que se travam na prática espacial, em vez de aceitar convenções que carregam significados políticos colonizadores:.

Por isso agora colocamos o mapa ao contrário, e então temos a exata ideia da nossa posição, e não da maneira que o resto do mundo quer. A ponta da América, a partir de agora, prolongando-se, marca insistentemente o Sul, o nosso norte. Igualmente nossa bússola: se inclina irremissivelmente sempre para o Sul, em direção 
ao nosso pólo. Os navios, quando partem daqui, baixam, não sobem, como antes, para viajar ao norte. Porque o norte agora está abaixo. $\mathrm{E}$ o leste, se estamos de frente para o nosso Sul, está à nossa esquerda. Esta retificação era necessária; por isso agora sabemos onde estamos. (TORRES-GARCÍA, 1984, p. 193).

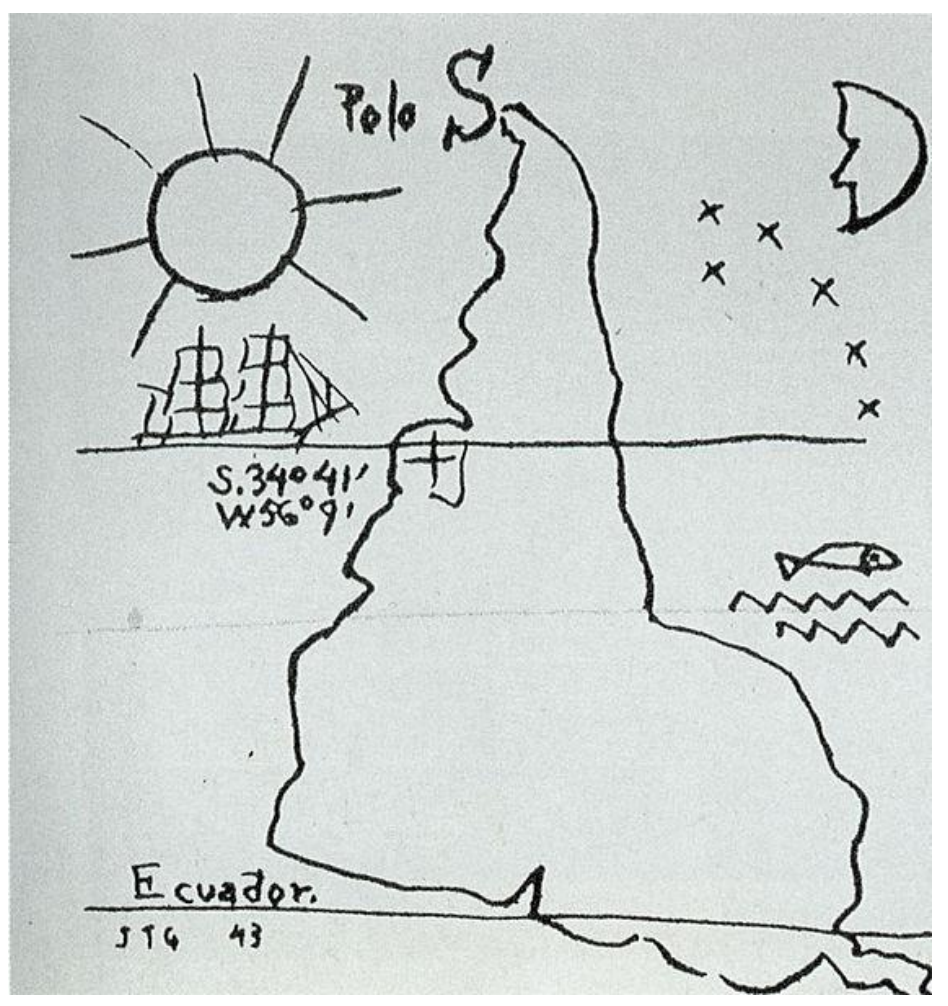

Figura 5 - A América do Sul invertida de Torres-García (1943) ${ }^{5}$

Boaventura de Sousa Santos ecoa em Portugal a visão de Torres García: em vez de falar de "Terceiro Mundo", inventa uma territorialidade que interliga o físico e o social: "[...] nós preferimos chamar simplesmente 'Sul', um Sul sociológico e não geográfico (não inclui os países centrais do Sul, como a Austrália e a Nova Zelândia)" (SANTOS, 2005, p.23). O Sul tem como significados a expropriação e a desigualdade, e tal construção semântica acopla ao mapa a noção de virtualidade e a experiência de outras categorias de distância. "A característica fundamental do pensamento abissal é a impossibilidade da copresença dos dois lados da linha. Este lado da linha só prevalece na medida em que esgota o campo da realidade relevante" (SANTOS, 2008, s/p.). O resto é inexistência e invisibilidade. A linha

\footnotetext{
${ }^{5}$ http://commons.wikimedia.org/wiki/File:Joaqu\%C3\%ADn_Torres_Garc\%C3\%ADa__Am\%C3\%A9rica_Invertida.jpg
} 
imaginária que divide o sul e o norte terrestre é entendida como o plano-muro que impossibilita a coexistência e que, historicamente, é rastro da visão das sociedades dominantes, daqueles que escrevem a história. Vive-se a herança de uma cartografia abissal como elemento constitutivo do conhecimento e das práticas coloniais. Nesse contexto de análise, novos mapas que tornam a situar os lugares em uma geometria crítica são construções necessárias e importantes armas epistemológicas e políticas. Agora sabemos onde estamos.

O pensamento pós-abissal pode ser sumariado como um aprender com o Sul usando uma epistemologia do Sul. Confronta a monocultura da ciência moderna com uma ecologia de saberes. É uma ecologia, porque se baseia no reconhecimento da pluralidade de conhecimentos heterogéneos (sendo um deles a ciência moderna) e em interacções sustentáveis e dinâmicas entre eles sem comprometer a sua autonomia. A ecologia de saberes baseia-se na idéia de que o conhecimento é interconhecimento. (SANTOS, 2008, $s / p$.$) .$

A noção de conhecimento como esquema trata o mundo como mapa, folha plana de papel com a qual se faz um abrigo frágil. Uma cartografia pós-abissal desenha um mundo policêntrico e polissêmico, expandindo as suas maneiras de reconhecimento. Mas para que o mapa deixe de ser um sistema cultural expresso pelo poder hegemônico, é necessário o seu descentramento: como escreveu Harley, as classes, gêneros, mitos e rituais cartográficos precisam ser praticados como discursos e sistemas culturais possíveis.

O mapa ressurge como ciência das qualidades em detrimento de campo das quantidades: ao mesmo tempo que estuda, analisa e produz um conhecimento espacial, o mapa propõe a ativação das alteridades do espaço, e aí reside o seu potencial político pós-abissal e a sua proposição como geografia coexistente. Enquanto prática propositiva, o mapa dá continuidade à história do mapa como relato, esse território de projeção da ciência-ficção sob a forma da dúvida, e não da certeza: hic sunt dracones?

Nas telas de Johannes Vermeer estão presentes mapas na parede e globos sobre os móveis, objetos constituintes do cenário doméstico (figura 6). Tais mapas demonstram tanto a popularidade desses artefatos como o grau de desenvolvimento 
estético dos mapas produzidos entre os séculos XVI e XVII na Holanda (WELU, 1987).

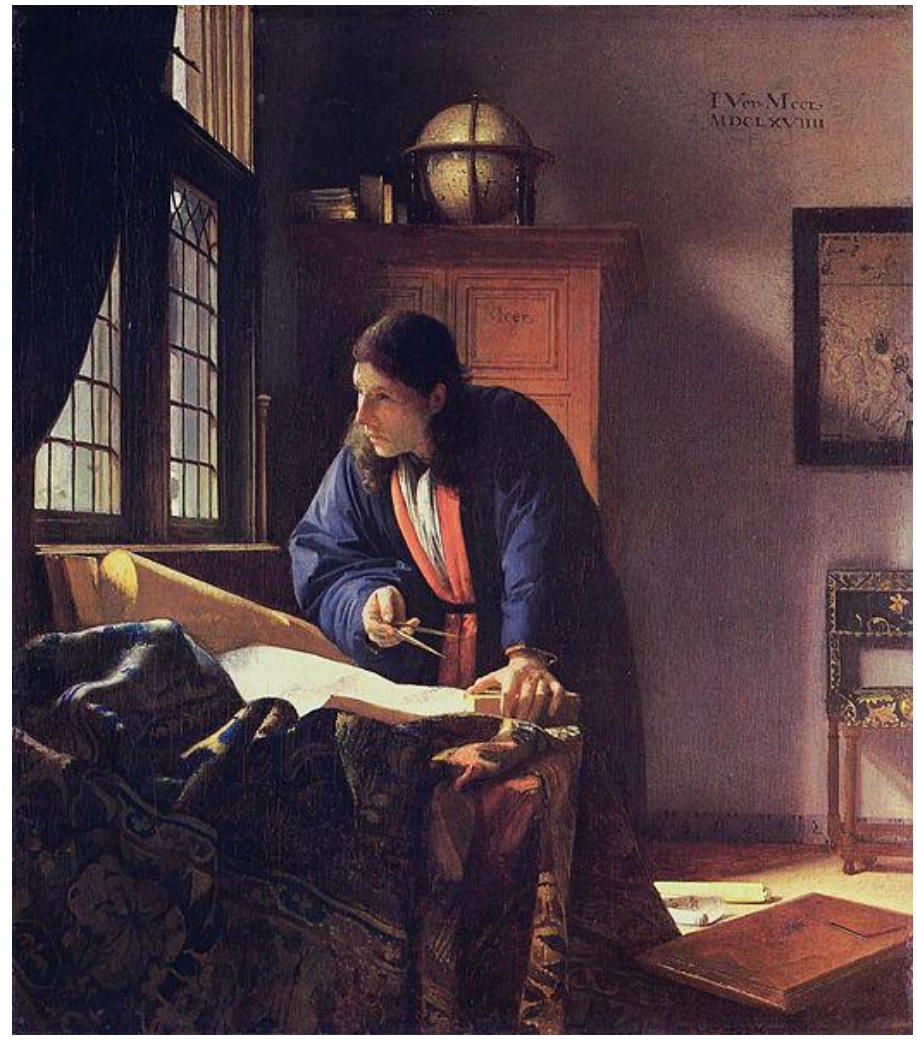

Figura 06: O Geógrafo de Vermeer (1668-69)

Mas, se o estudo se detiver um pouco mais nas telas, pode-se chegar à conclusão de que os mapas não são meros objetos de cena e sim personagens da pintura. Nos interiores retratados por Vermeer, é construída uma compreensão de mundo na qual as imagens cartográficas encarnam a obsessão de conhecer e dialogar com esse conhecimento. Os supostos objetos cartográficos - em tapeçarias, pinturas, globos - povoam o doméstico e as suas histórias: um encontro, uma carta recebida, um astrônomo, um geógrafo. Povoam: o mapa que posa para Vermeer é atuante como as figuras humanas que convivem com ele e constroem, juntos, a história da ação. A leitura que se faz dos mapas de Vermeer não é a leitura de localização e navegação, mas a leitura de deslocamento, de evasão.

\footnotetext{
${ }^{6}$ http://en.wikipedia.org/wiki/File:J._VERMEER_-

_El_ge\%C3\%B3grafo_\%28Museo_St\%C3\%A4del,_Fr\%C3\%A1ncfort_del_Meno,_1669\%29.jpg
} 
Ao contrário do que demonstrou Richard Wollheim, que escreveu que a representação da cartografia e a representação da pintura demandam distintas percepções - para o autor, o mapa é uma convenção de legibilidade em vez de uma representação que é percebida na sua densidade - os mapas de Vermeer são empregados na criação da heterotopia doméstica.

Esse fato sobre mapas e o que eles mapeiam é confirmado pelo modo como extraímos deles as informações que contêm. Para fazêlo, não necessitamos de uma capacidade de percepção natural, de um olhar denso. Utilizamos uma habilidade que aprendemos. Ela é chamada, significamente, 'leitura cartográfica': 'leitura cartográfica' (WOLLHEIM, 1987, p. 61).

Nas pinturas de Vermeer, figuras clássicas nos livros de geografia, a atmosfera pulsa com tanta qualidade que não se distingue mais o ver do ler: entrase no mundo do século XVII tanto pelas janelas domésticas de Vermeer como pelos mapas pendurados nas suas paredes. Janelas múltiplas, de uma multiplicidade dinâmica, são o quadro pintado, o mapa, a janela da casa, a viagem imaginada. Michel de Certeau lembra-nos da propriedade voraz da geografia de transformar ação em legibilidade (CERTEAU, 1994). Mas as práticas espacias - cotidianas ou artísticas - estão frequentemente a serviço da desconstrução dessa legibilidade, do rompimento com a sua sintaxe.

\section{"Sob a chuva abro um mapa-mundi."}

Um micro-poema de Joan Brossa (BROSSA, 2005, p. 93). Um outro dispositivo, séculos depois de Vermeer, capaz de fazer o mapa conversar com o mundo, abrindo a ciência moderna para os seus desdobramentos térreos e heterogêneos. Nesse ato poético de Brossa, tem-se a criação de uma imagem em conflito: simultaneamente varrida por escalas desproporcionais, aproxima e refuta componentes no seu processo de autoajuste. Trata-se de uma ação diminuta e ao mesmo tempo dotada de grande poder de fabulação ${ }^{7}$; uma experiência na qual se perdem a calibração da referência de escala e os parâmetros quantitativos.

\footnotetext{
${ }^{7}$ Gilles Deleuze e Felix Guattari resgatam Henri Bergson, que fala da fabulação como uma faculdade visionária, distinta da imaginação, que cria potências ou presenças eficazes, "fabricação de gigantes". Segundo o autor, a fabulação, apesar de exercer-se inicialmente na religião, desenvolve-se livremente na arte e na literatura (DELEUZE; GUATTARI, 1997, p. 218).
} 
Mesclam-se, nessa ocasião, a matemática e a sensação; o espaço abstrato e o espaço vivido. Fica criada uma redundância e a sua ficção, no momento em que o mundo dentro do mundo precisa ser assim posicionado para que se reconheça como tal. O mapa necessita ser levado ao mundo, ao passo que o mundo se abriga, por precisão científica, no mapa. O mapa como abrigo é então, no poema de Brossa, uma dupla construção: arquitetônica e epistemológica.

Dessa construção arquitetônica decorrente de um gesto, surge uma ambiência potente embora temporária. Fica suspenso o mapa-mundi, e fragmentase a suposta totalidade do conhecimento num núcleo construtivo primário. Desmontam-se as imagens iconográficas da cartografia na busca incerta da formulação de uma geografia da experiência. Chove no mapa. Tal fenômeno é uma imagem do mundo tentando penetrar na sua representação; a natureza reafirmando o seu ímpeto na assepsia da cartografia. Entendida como construção epistemológica, a ação evocada pelo poema trata da experiência corpórea dessa ambiência temporária como uma fuga da linguagem modelar, como um vetor de retorno ao território. A escala do corpo desvela a dimensão subjetiva da experiência geográfica.

Sendo assim, o que ocorre quando o mapa se transforma em coisa-em-ação, para além da sua função instrumental de ser legível? Aí, a sua propriedade comunicacional desdobra-se de leitura cartográfica para uma densidade perceptiva ou uma prática espacial. Em vez de manifestação territorial singular, o mapa pode ser reinstrumentalizado como manual, dispositivo de novos relatos, guia para navegações cotidianas que vão além do seu lugar-matriz.

O povoamento, que é a aplicabilidade do mapa, finalmente molda-se ao corpo do mapa. Em vez de territorializar, o mapa agora se desterritorializa, pois o modo de povoar que ele propõe é transferido para outros lugares possíveis, desdobráveis daquele que representa (pois o mapa é apenas um lugar-matriz do pensamento espacial). A ambulância do modo de povoar e a transferência sucessiva de territórios aproximam o mapa heterotópico de um manual de navegação diletante.

Por navegação entende-se o ato de operar, controlar, guiar algo ou alguém no trânsito de um lugar a outro. O tempo é matéria da navegação e, em conjunto com o espaço, solicita os nossos meios de percepção e de interferência no processo 
do deslocamento. A navegação pressupõe uma duração e não simplesmente uma ou mais localizações (a localização é a especialidade dos mapas, que fixam as coordenadas e as distâncias). O estado navegador faz confundir, na lei da relatividade da observação, a viagem com o caminho: os lugares parecem se afastar ou se aproximar das pessoas à medida em que essas viajam e a própria viagem abre-se como possibilidade efetiva de atuar como um lugar ela mesma. A viagem então torna-se a instalação de um lugar não fixável, cuja bússola titubeia e cujo território escapa a cada novo passo.

Esquadrinhando rotas, práticas artísticas reescrevem a relação entre algo ou alguém e o seu trânsito no espaço, propondo navegações de extravio para a sobrevivência em terra firme. Lugares concretos mesclam-se com novos lugares vividos sobre os primeiros, alteridades do espaço que revelam como o sistema artificial que se costuma chamar de geografia pode ser desdobrado em muitos outros sistemas cognitivos.

Mas em que consiste a navegação de extravio? O extravio é a condição de busca pelo Outro e recusa do Mesmo (FOUCAULT, 2000); o desejo político de construir outros espaços e relações espaciais; o ímpeto de tecer as formas da complexidade humana que não se permitem conter nas normas do Mesmo. Extraviar-se é perder-se para poder encontrar-se, distrair-se para poder concentrarse, aventurar-se para poder voltar à casa. Extraviar-se como o ato de negar-se duplamente: aos sentidos geolocalizadores $e$ aos sentidos dos nomes preestabelecidos às coisas, construindo nesse processo uma geolocalização e uma taxonomia próprias.

"O outro caminho, que entretanto é o mesmo."

Escreveu Julio Cortázar em plena navegação (CORTÁZAR; DUNLOP, 1996, p.56). O escritor desabilita o nome-etiqueta das coisas mediante um encontro, situação espacial que define para ele, de modo sempre inaugural, a realidade. Jaime Alazraki, no prólogo que preparou para a edição venezuelana de 1988 de Rayuela, livro de Cortázar, escreveu que Cortázar alinha-se com Jorge Luis Borges na perseguição do caráter alucinatório do mundo, buscando e demonstrando os vestígios desse caráter. Cortázar, particularmente, investigaria o naufrágio da cultura 
e o extravio do homem, escrevendo o mapa desse extravio, como definiu Alazraki. A arte como veículo epistemológico operaria em resposta "aos novos critérios de descontinuidade e indeterminação cm que trabalha a ciência contemporânea" (CORTÁZAR, 1988, p.LIX.).

[...] quase nunca aceitei o nome-etiqueta das coisas e creio que isso se reflete nos meus livros, não vejo porque tolerar invariavelmente 0 que nos vem de antes e de fora, e assim aos seres que amei e que amo fui destinando nomes que nasciam de um encontro, de um contato entre chaves secretas [...] (CORTÁZAR; DUNLOP, 1996, p. 23).

Nos escritos de Cortázar encontramos sempre uma espécie de fuga do mundo ordinário, mas a condição dessa fuga é justamente um mergulho radical no mundo e o esquadrinhamento das suas possibilidades como alteridade. Um saber que é baseado numa descontinuidade: uma epistemologia que se afasta para se aproximar, que extravia o encontro com o cotidiano para dar precisão aos seus mapas.

O que Cortázar chama de mítico nasce justamente da experiência; o mito é uma relação cognitiva fabricada - como todas as relações cognitivas, enfim - que torna o real uma série de passagens, pontes, signos e descobrimentos, ou seja, que faz do real um território transitável. Os escritos de Cortázar cartografam, num estado assumidamente ambulatório, a existência de fundos falsos nos espaços, de paisagens que se desdobram em outras paisagens até então não experimentadas.

[...] esse estado ambulatório em que, num momento dado, deixamos de pertencer ao mundo ordinário, me situa com respeito à cidade e situa a cidade com respeito a mim em uma relação que os surrealistas chamavam de "privilegiada". Isto é, nesse preciso momento se produzem a passagem, a ponte, as osmoses, os signos, os descobrimentos. [...] Caminhar por Paris - e por isso qualifico Paris como cidade mítica - caminhar por Paris significa avançar em direção a mim. ${ }^{8}$

Se o surrealismo (sur réalisme: uma outra realidade sobreposta) a que se refere Cortázar criou um lugar para o sobrerreal, unindo formas e ações díspares segundo as convenções culturais, as deambulações de Louis Aragon, André Breton,

8 Depoimento de Julio CORTÁZAR à TVE francesa. Disponível em: <http://www.youtube.com/watch?v=JDfYGOBIsjA> Acesso em: 01 de set. de 2013. 
Max Morise e Roger Vitrac, na década de 1920, dando continuidade histórica às flâneries da metade do século XIX e às deambulações dadaístas dos primeiros anos do século $X X$, experimentam o inconsciente do território. Um território é inconsciente quando funciona de forma automática, ou seja, independente de decisões e encaminhamentos ditos conscientes e se conserva enquanto tal na dificuldade de acessibilidade. O inconsciente do território é então a camada profunda dos desejos, instintos e recordações reprimidas.

As andanças surrealistas iam na contramão do ritmo orientador e consciente da cidade e buscavam a experiência da desorientação e da falta de controle - uma navegação sem manual - para que outras forças não objetivas e não conscientes protagonizassem um relato espacial. "A viagem, empreendida sem finalidade e sem objetivo, converteu-se na experiência de uma forma de escritura automática no espaço real, numa errância literária/campestre impressa diretamente no mapa de um território mental” (CARERI, 2002, p.82). O espaço e a (in)consciência dele (território mental) aparecem como um entidade só, comunhão conseguida no estado ambulatório e que reforma o espaço e os seus descobrimentos.

Nas palavras de Cortázar, caminhar "significa avançar em direção a mim". Para ele, o estado especial de quem deambula não consiste necessariamente em privilegiar o contato com a inconsciência do território, mas de travar uma geografia portátil (MARQUEZ, 2009) que estabelece um conjunto de significados e de consciências de si e dos outros, criando uma situação a partir da qual o espaço se redesenha. Por outro lado, da mesma forma que para os surrealistas e também para os situacionistas, caminhar funciona como um medium, um procedimento capaz de cartografar o próprio escritor. Mas esse medium assemelha-se mais a uma espécie de antropologia do que a uma prática de psicanálise; a ciência em suas diversas formas de apreensão é evocada por Cortázar inúmeras vezes nas páginas dos seus livros. Em vez de uma escritura automática no espaço real, é proposta uma escritura cotidiana sobre lugares eleitos para se viver, um manual de navegação baseado num trajeto planejado e inserido no fluxo veloz das cidades, das rodovias intermunicipais e, igualmente, nas suas condições sucessivas de desaceleração.

E assim, de vez em quando, deixo de trabalhar e vou às ruas, entro em um bar, observo o que acontece na cidade, dialogo com o velho 
que me vende salsichas para o almoço porque o dragão, já é tempo de apresentá-lo, é uma espécie de casa sobre rodas ou caracol que as minhas obstinadas predileções wagnerianas definiram como dragão, um Volkswagen vermelho no qual há um tanque de água, um assento que se converte em cama e a isso somei um rádio, a máquina de escrever, livros, vinho tinto, latas de sopa e copos de papel, calção de banho (se por acaso), uma lâmpada a gás e um aquecedor graças ao qual uma lata de conservas converte-se em almoço ou jantar enquanto se ouve Vivaldi ou se escrevem estas páginas (CORTÁZAR; DUNLOP, 1996, p. 23.).

Em seu último livro, Cortázar relata o planejamento, a experiência e as estratégias de uma viagem empreendida de Paris a Marseille. O livro, escrito-vivido com Carol Dunlop, inclui algumas fotografias da rodovia por onde eles transitam, com a legenda "A rodovia dos outros". Nessas imagens, paira sempre um olhar distanciado, pois na fotografia não aparecem nem Cortázar nem Dunlop, os protagonistas da expedição, nem Fafner, o Volkswagen Kombi vermelho, meio de transporte eleito à condição humanizada de personagem. Claro está que aquela paisagem retratada não lhes pertence, é a rodovia dos outros: banal, sem qualidades atrativas, um não-lugar ou lugar de mera passagem (AUGÉ, 1994), onde o movimento significa simplesmente vencer distâncias e no qual parar implica severamente perder tempo de viagem. Mas a rodovia que une Paris a Marseille mostra-se bem diferente para o casal de expedicionários. Eles projetam a viagem para viver a intensidade daquele espaço em movimento, transformado em espaço de possibilidades. Esse não-lugar, de 23 de maio a 23 de junho de 1982 e por intermédio de regras práticas cotidianas, foi convertido em verdadeiro lugar antropológico - antropologia de si mesmo e dos outros - e em campo de observações amadoras e diletantes (literárias) de botânica e zoologia.

"Um livro de viagem. Como os antigos exploradores" (CORTÁZAR; DUNLOP, 1996, p.36)

No livro se encontram referências ao Capitão Cook, à Vasco da Gama e a Cristóvão Colombo, cujos relatos de expedição deram inspiração culinária e promessa de surpresas a Cortázar e Dunlop. Assim, resolvem cumprir o trajeto sem sair da rodovia, explorando cada parada da estrada, numa média de duas por dia, num total de sessenta e cinco paradas. Em cada uma, classificada como "pequena 
cidade efêmera", "cidade mais internacional do mundo" e "cidade fantasmal", anotam as observações relevantes em um (composto de duas vozes) diário de bordo. O livro Los autonautas de la Cosmopista, de 1983, é uma prática de travelogue, uma narração ilustrada de viagem, um diário-diálogo de bordo. Discurso para uma trajetória ou manual de navegação, compilação de impressões espaciais ao mesmo tempo que íntimas, a cosmopista torna-se o logos cartografado. Os autores criam uma lógica de ocupar o espaço, uma rota literária avessa ao pragmatismo e alheia à planura das paisagens típicas dos não-lugares, concretizadas pelos sinais de comunicação das regras de circulação.

A rodovia deles e a rodovia dos outros encarna a evidência da portatibilidade do espaço, quando caminhar significa avançar em direção a si mesmo. "É que os estacionamentos não são outra coisa além de cenários vazios. É preciso saber preenchê-los. E, apesar das diferenças geográficas ou físicas, sempre são o mesmo" (CORTÁZAR; DUNLOP, 1996, p.139). A expedição de Paris a Marseille através da rodovia Outra gera um manual de navegação aplicável, uma vez que busca as linhas de fuga do espaço inicialmente inóspito e o desenho efêmero de uma prática espacial transformadora, intervencionista.

Para discutir o caráter de intervenção da expedição, há um trecho de Los autonautas de la Cosmopista no qual Cortázar lê a notícia de que o Presidente da Associação das Sociedades Francesas de Rodovias - a quem já tinha se dirigido por carta na etapa de preparação da expedição, sem no entanto receber qualquer resposta - lançava um comunicado destinado à Academia de Belas Artes no qual reconhecia a necessidade de "humanização" da rodovia, destinando até $2 \%$ dos investimentos à criação artística. Cortázar, não sem ironia, desloca a idéia de "arte pública" para o manual de navegação do espaço público, diluindo o desejo de "humanização" para a prática espacial personalizada. Em vez de adereços que previam uma coletividade abstrata e equivocadamente homogênea, o imaterial travelogue poderia materializar-se, mais democraticamente e como procedimento, no porta-luvas dos carros.

E agora querem artistas, o senhor Rickart clama pelo embelezamento das rodovias! Quem ou o que vai embelezá-las melhor do que nossa deliciosa crônica? Artistas da pena, pintores de atmosferas, escultores de instantes privilegiados erigidos para 
sempre sobre o pedestal das palavras, para que cada usuário das rodovias possa levar no porta-luvas do seu carro a condensação estética dessa fita branca que recorre, dessas ilhas verdes (na maioria das vezes) onde ele se deterá para o espairecimento e os sanduíches preferidos. Não nos adiantamos aos seus desejos, senhor Rickart? Não estamos dando à França de hoje um bom exemplo de que a imaginação pode realmente tomar o poder quando se esquece das rotinas? (CORTÁZAR; DUNLOP, 1996, p.320).

\section{"Aplanar o esférico" aparece nas páginas de Los autonautas de la Cosmopista} como uma tática de descobrimentos e percepções da geografia do mundo, em uma gama variada de escalas. De fato, Julio Cortázar aplana o mundo esférico na máquina de escrever, como um cartógrafo moderno que calcula a matemática da projeção da localização. O seu cálculo transforma as operações com números em uma geometria de palavras e frases, uma métrica de sentidos. Essa matemática dos sentidos é a inteligência que abole a distância entre os autores e a paisagem e os fazem conviver com os outros proprietários efêmeros dos lugares. Cortázar e Dunlop deslocam as ferramentas geotécnicas e taxonômicas para que elas sejam empregadas em outros domínios espaciais.

Cartografia do país de uma árvore: por que não? Bastaria uma série de fotos precisas e a paciência de aplanar o esférico, como Mercator, como os fazedores de portulanos, aqui o norte ou o leste, aqui o alto e o baixo, os Everestes e os Mediterrâneos da árvore. Imagino o mapa da minha árvore, com os seus signos convencionais, seu azul e seu verde e seu branco, a hidrografia e a hipsometria e a orografia e por que não sua etnologia (sua entomologia e sua ornitologia). Imagino o cartógrafo desenhando na escala da página o torvelinho esférico da árvore, mostrando as rotas que do fuste central - rodovia da árvore - tendem suas bifurcações a um e outro lado, separando por sua vez em dois, quatro, cinquenta, duzentos, mil oitocentos e quarenta e quatro caminhos menores que se perdem em dezenas de milhares de caminhos, cada um com seus campos verdes, cada folha uma parcela do cadastro e em cada parcela um propietário efêmero - como deveriam ser todos - o mosquito, a aranha, o bicho-da-seda, a joaninha, e até esses seres imperceptíveis que terão um nome nos tratados mas que aqui, sobre esta máquina de escrever, traçam de vez em quando a imagem infinitesimal de um animalzinho que avança em direção às teclas, vacila na borda, retrocede e se perde no primeiro segundo de desatenção, já esquecido, já nada. (CORTÁZAR; DUNLOP, 1996, p.123).

Tudo aquilo que foge ao interesse dos guias Michelin parece atrair a atenção dos expedicionários do Fafner, que observam os insetos mais amistosos e os 
motoristas nem tão amistosos assim, incluindo aqueles dos gigantescos e intimidadores caminhões Sopa Speedy ou France Macaron. Em nome da respeitosa ciência, cujo espírito alegórico dá respaldo à questionável seriedade da expedição, o cotidiano povoado por seres alheios à rodovia é verificado minuciosamente e a busca pela possibilidade de uma história natural torna-se uma aventura à margem dos áridos acostamentos. Nas paradas, o mundo se recompõe em vegetação, seres humanos surpreendentemente saem das máquinas-carros ("coisas") e o encontro com os insetos sugere mundos paralelos e uma inversão da posição de intruso: quem incomoda quem? Rapidamente, aranhas, lesmas, joaninhas, besouros, bichos-da-seda, formigas ferozes e libélulas remotas passeiam na máquina de escrever posicionada ao ar livre, um microcosmo duplo (as letras e os insetos) em cuja paisagem a rodovia é apenas um cinema distante, como era mesmo o seu desejo de ser: cinema calibrado em centenas de quilômetros por hora - em vez de quadros por segundo.

"Cada árvore um mapa diferente (e efêmero, mas assim são todos os mapas), uma intenção individual de caminhos, encruzilhadas, passagens e pontes" (CORTÁZAR; DUNLOP, 1996, p.124). Desta forma, Cortázar define o trabalho inesgotável do cartógrafo no qual se converte: intenção individual, registro de efemeridades, territórios desdobráveis em outros territórios com formas pouco convencionais para um mapa (como o é uma árvore). Se o imaginário da árvore pode gerar um mapa, se as suas formas, hierarquias e conexões esquematizam um território sem metáforas, a rodovia que une Paris a Marseille transforma-se em um continente a ser explorado, desdobra-se na "rodovia paralela" (CORTÁZAR; DUNLOP, 1996, p.56), nesse "diálogo feito viagem" (CORTÁZAR; DUNLOP, 1996, p.204), um sistema estimulador disponível a qualquer um que o deseje.

Nós, por outro lado, levamos três semanas dentro de um sistema estimulador que só se modifica parcialmente (maior ou menor número de estímulos segundo a topografia e a índole da parada) que ao repetir-se cada noite acabou provocando diretamente um tipo de sonho, que finalmente se impôs frente à nossa atenção e às nossas observações. (CORTÁZAR; DUNLOP, 1996, p. 311).

Nesse trabalho de campo muitas vezes refém da precariedade, apesar de "[...] ver que a organização científica e doméstica da expedição está bem 
estabelecida" (CORTÁZAR; DUNLOP, 1996, p.128), havia patrulhas de salvamento programadas: amigos vinham periodicamente (e raramente, para o próprio sucesso da expedição) com alimentos frescos para protegê-los da ameaça do escorbuto; hotéis e banhos quentes eram quase frequentes; cardápios tão glamurosos quanto singelos (quinta, 27 de maio: almoço - espaguete com molho caseiro, cerejas, café; jantar - ovos cozidos, queijo, café) eram postos a funcionar no acolhedor Fafner; e havia a companhia de um rádio que fornecia, dentre outras, as notícias da guerra das Malvinas. Música, livros, câmera fotográfica e as duas máquinas de escrever juntam-se aos outros detalhes cotidianos, tornando a vida na rodovia saudável e promissora.

$E$, ao final, puderam realizar o segundo objetivo da expedição (até então não revelado, que faz par com a finalidade primeira e óbvia do conhecimento detalhado da rodovia) que consiste numa verificação simples mas necessária: "Existe Marseille?" Foi comprovado: "Marseille existe, e é tal como é mostrada por Marcel Pagnol. Mas só existe porque a expedição verificou a sua existência, e não pelas razões que o vulgo aceita sem análise prévia" (CORTÁZAR; DUNLOP, 1996, p.286). O universo literário de Cortázar invade o espaço científico (ou deixa-se por ele invadir) - da geografia, da engenharia de tráfego, da botânica, da zoologia, da entomologia e também o espaço do senso comum (o vulgo anestesiado pelos nãolugares e submerso no Mesmo), chamando para si a autoria de uma invenção que, se parar para pensar, é inerente a toda e qualquer construção lógica.

\section{CONCLUSÃO}

A cartografia é contextualizada neste ensaio não a partir da neutralidade e da objetividade inerentes às suas características como campo das quantidades, mas a partir da proposta de entendê-la como ciência das qualidades. Através do esforço criativo de produção de um conhecimento que se deixa contaminar por outras experiências perceptivas do mundo, vindo de artistas que se dedicam a observar criticamente o seu entorno, a cartografia torna-se assim capaz de exercer, na sua prática ampliada de esquadrinhar e conhecer os espaços, o olhar indagador frente aos fatos naturalizados como dados e fixos e, consequentemente, torna-se capaz de 
fomentar o imaginário prospectivo para a potência coletiva e transformadora dos nossos espaços atuais.

\section{REFERÊNCIAS}

AUGÉ, Marc. Não-lugares: introdução a uma antropologia da supermodernidade. Campinas: Papirus, 1994.

BROSSA, Joan. Poesia vista. São Paulo: Amauta Editorial, 2005.

CARERI, Francesco. Walkscapes. El andar como práctica estética. Barcelona: Gustavo Gili, 2002.

CERTEAU, Michel de. A Invenção do cotidiano. 1. Artes de fazer. Petrópolis/RJ: Vozes, 1994.

CORTÁZAR, Julio. Cuentos completos 2. Buenos Aires: Punto de Lectura, 2007.

CORTÁZAR, Julio; DUNLOP, Carol. Los autonautas de la cosmopista o un viaje atemporal París-Marsella. Madrid: Alfaguara, 1996.

COSGROVE, Denis. Apollo's eye. A cartographic genealogy of the Earth in the Western imagination. Baltimore: The Johns Hopkins University Press, 2001.

COSGROVE, Denis; MARTINS, Luciana Millennial Geographics. In: MINCA, C. (ed). Postmodern geography: theory and praxis. Oxford/Malden: Blackwell Publishers, 2001.

DIEGO, Estrella de. Contra el mapa. Madrid: Siruela, 2008.

FOUCAULT, Michel. As palavras e as coisas. São Paulo: Martins Fontes, 2000.

HARLEY, John Brian. Deconstructing the map. In: BARNES, Trevor; DUNCAN, James S. (Orgs.). Writing worlds. Discourse, text and metaphor in the representation of landscape. New York: Routledge, 1992, p. 231-247.

MARQUEZ, Renata Moreira. Geografias portáteis: arte e conhecimento espacial. 2009. Tese de Doutorado. Instituto de Geociências, UFMG. Belo Horizonte.

MASSEY, Doreen. Pelo espaço: uma nova política da espacialidade. Rio de Janeiro: Bertrand Brasil, 2008.

PEREC, Georges. Especies de espacios. Mataró (Barcelona): Montesinos, 2007.

SANTOS, Boaventura de Sousa. Para além do pensamento abissal: das linhas globais a uma ecologia de saberes. Eurozine. Viena, 14 de fev. de 2008. 
<http://www.eurozine.com/articles/article_2008-02-19-santos-pt.html> Acesso 01 de set de 2013.

Semear outras soluções: os caminhos da biodiversidade e dos conhecimentos rivais. Rio de Janeiro: Civilização Brasileira, 2005.

TORRES-GARCÍA, Joaquín. Universalismo constructivo, 1. Madrid: Alianza Editorial, 1984.

WELU, James $A$. The sources and development of cartographic ornamentation in the Netherlands. In: WOODWARD, David (Org.). Art and cartography: six historical essays. University of Chicago Press, 1987, p.147-173.

WOLLHEIM, Richard. Painting as an art. London: Thames and Hudson, 1987. 